\title{
TITLE:
}

\section{$<$ Note> Eleven-Year Old Male Chimpanzee Outranks Ex-Alpha Adult Male at Bossou}

\section{AUTHOR(S):}

Nakamura, Michio; Ohashi, Gaku

\section{CITATION:}

Nakamura, Michio ... [et al]. <Note> Eleven-Year Old Male Chimpanzee Outranks Ex-Alpha Adult Male at Bossou. Pan Africa News 2003, 10(1): 911

ISSUE DATE:

2003-06

URL:

http://hdl.handle.net/2433/143421

RIGHT:

Copyright (C) Pan Africa News. 
troglodytes) is usually measured by the pant-grunting vocalization directed from the subordinate to the dominant $(1,2)$. Although a linear dominance hierarchy exists among most adult males, some dyadic relationships are ambiguous $(1,3)$. In contrast, there is a distinctive social gap between adult males and adolescent males, i.e. all adolescents pant-grunt to all adults (4). Adolescence in male chimpanzees is thus a period between sexual maturity and social maturity which is achieved at about 15 years of age $(5,6,7$ but see 8$)$. We report here the case of $Y L$, a young male at Bossou, who outranked an old ex-alpha adult male TA and became the beta male at the age of 11 years, and who also showed insubordination to the alpha male $F F$.

\section{Methods}

Wild chimpanzees have been continuously studied at Bossou, Guinea since 1976. In more than two decades, there has been little change in the group size (8), which is currently 19 including two adult males. Ohashi followed FF for 1210 hours from Jul. 2002 to Mar. 2003, and Nakamura followed 9 individuals including all four of the sexually mature males (Table 1 ) for 241 hours from J an. to Mar. 2003. Observations were made during focal follows that included non-focal individuals around the target subjects.

\section{Observations}

$Y L$ (Figure 1) pant-grunted to TA until at least J an. 2003, but no pant-grunts were heard after that. $Y L$ was completely subordinate to $F F$ until early Feb. 2003, showing exaggerated pant-grunts characteristics of adolescent males.

On 8th Feb. 2003, TA showed sexual possessiveness to an estrous female $F n$ in the party that included $Y L, P O$ and some others. $P O$ copulated stealthily with $F n$, which caused great uproar in the party, and $Y L$ and $T A$ displayed at each other. Neither pant-grunted, but finally $T A$ grimaced, screamed, and sought assurance from $Y L$. After that, $T A$ groomed first with $Y L$ 's mother $Y o$ who had rushed to the uproar, and then with $Y L$ for about 30 minutes.

In the next evening, while $T A$ and $Y L$ ate Introduction

Dominance among chimpanzees (Pan Rhaphiostylis beninensis fruits with six other 


\begin{tabular}{|c|c|c|c|c|}
\hline \multirow{2}{*}{$\begin{array}{lr}\text { chimpanzees, } & T A \\
\text { began to } & \text { make } \\
\text { opportunistic } & \end{array}$} & \multicolumn{4}{|c|}{ Table 1 Four Mature Males at Bossou. } \\
\hline & Name (Abbr.) & Year of Birth & Age in 2003 Mar. & Mother \\
\hline displays around $F n$. & Tua $(T A)$ & unknown (adult in 1976) & old & unknown \\
\hline When $F n$ screamed, & Foaf $(F F)$ & 1980 late & 23 & Fana (alive) \\
\hline$Y L \quad$ also & Yolo $(Y L)$ & 1991 middle & 11 & Yo (alive) \\
\hline splay and when & Poni $(P O)$ & 1993 Feb. & 10 & Pama (alive) \\
\hline
\end{tabular}

approach pant-grunted to $Y L$.

On 18th Feb. 2003, TA and $P O$ ranged away from others. When they reunited with $Y L$ that evening, $T A$ pant-grunted without $Y L$ displaying or showing aggression.

As $F F$ was ranging far to the north in consortship with a female from 8th to 21st Feb, it is possible that $T A$ 's submissive behavior to $Y L$ was temporary, because of the absence of support from $F F$. However, on 2nd Mar., TA pant-grunted to $Y L$ when $F F$ was in the nearby tree, so it was obvious that $Y L$ dominated $T A$ and was now the beta male.

After $F F$ 's return, $Y L$ never pant-grunted to $F F$ except for once on 22nd Feb. $Y L$ tended to walk away from $F F$, but when he met $F F$ he sometimes displayed from a distance of $10-20 \mathrm{~m}$ standing bipedal and swaying his arms with hair erection. For a while, $F F$ made no aggression against $Y L$ 's insubordination except for displaying back, but on 12th Mar., FF beat $Y L$ out of the tree of Ficus umbellata. Unfortunately, this was the last day of our research at Bossou, so

we could not follow further devel opments.

\section{Discussion}

Eleven years old is a very young age to outrank any adult males and to show insubordination to the alpha male. We propose four mutually non-exclusive explanations for this.

(1) Demography: With only a few mature males, it may be difficult for older males to maintain status higher than their actual physical strength by using coalitions or alliances, with other males.

(2) Mother's proximity: $Y L$ 's mother, $Y_{O}$, had no children younger than $Y L$, and she often followed and stayed near $Y L$. She sometimes engaged in fights with males, so her proximity may have indirectly helped $Y L$ to raise rank.

(3) Early physical growth: It is possible that nutrition is better in Bossou than other places, because of the cultigens in their diet.

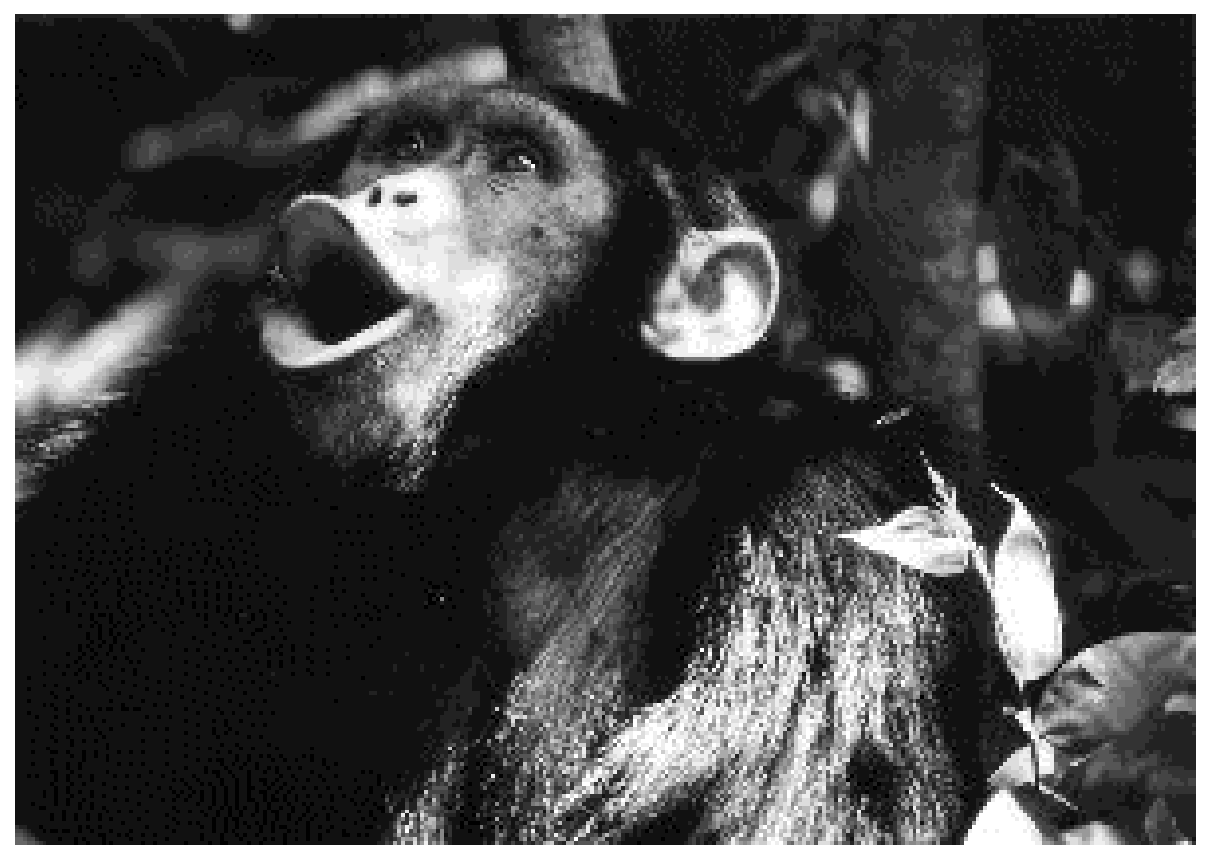

Figure 1. Eleven-year old male Yolo ( $Y L)$ 
$Y L$ looked much bigger than typical 11 year-old males and almost equaled adults at Mahale. Sugiyama (8) treated 12 years as adult at Bossou instead of the usual 16 years. Also, females at Bossou have their first birth more than three years younger than females in other wild populations (9). These also imply that physical growth is generally earlier in Bossou. This is not the difference between subspecies, because Taï chimpanzees (same subspecies as Bossou) do not seem to have this earlier growth (7).

(4) TA's old age: TA was prime adult in 1976 (8), which made him at least 45 years old in 2003. It is possible that he was forced by aging to give way to the young.

This report implies that chimpanzee males have the potential to rise in rank earlier than usual, under some conditions such as early physical growth and few social constraints. However, large body size is not enough to attain higher rank, as one male in Mahale, Bembe, had been low-ranking although he was large-bodied. If there are many adult males in the group, older males may skillfully exploit the histories of relationships with other adults to maintain higher social status than the physically developed but young males.

\section{References}

(1) Bygott J D 1979. Agonistic behavior, dominance, and social structure in wild chimpanzees of Gombe National Park. In: The Great Apes, Hamburg DA, McCown ER (eds), Benjamin/Cummings, Menlo Park, pp: 405-427.

(2) de Waal FBM 1982. Chimpanzee Politics. The J ohns Hopkins University Press, Baltimore.

(3) Nishida T, Hosaka K 1996. Coalition strategies among adult male chimpanzees of the Mahale Mountains, Tanzania. In: Great Ape Societies, McGrew WC, Marchant LF, Nishida T (eds), Cambridge University Press, Cambridge, pp.114-134.

(4) Hayaki H, Huffman MA, Nishida T 1989. Dominance among male chimpanzees in the Mahale Mountains National Park, Tanzania: a preliminary study. Primates 30:187-197.

(5) Goodall J 1983. Population dynamics during a 15 year period in one community of freeliving chimpanzees in the Gombe National Park, Tanzania. Z Tierpsychol 61:1-60.
(6) Hiraiwa-Hasegawa M, Hasegawa T, Nishida T 1984. Demographic study of a large-sized unit-group of chimpanzees in the Mahale Mountains, Tanzania: a preliminary report. Primates 25:401-413.

(7) Boesch C, Boesch-Achermann H 2000. The Chimpanzees of the Taï Forest. Oxford University Press, Oxford.

(8) Sugiyama $Y$ 1999. Socioecological factors of male chimpanzee migration at Bossou, Guinea. Primates 40:61-68.

(9) Fujita S 2003. Reproductive Biology in Wild Female Primates: Variety in Hormonal Profiles, Behavior and Reproductive Parameters. Ph.D. Dissertation, Kyoto University, I nuyama. 